\title{
Addressing HIV-related stigma and discrimination in healthcare settings: development and contextualization of guideline recommendations
}

\author{
Garumma Feyissa ( $\sim$ garummatolu@yahoo.com ) \\ Jimma University https://orcid.org/0000-0001-6179-0024 \\ Mirkuzie Woldie \\ Harvard School of Public Health
}

Zachary Munn

The Joanna Briggs Institute

Craig Lockwood

The Joanna Briggs Institute

\section{Research note}

Keywords: Guideline development, guideline evaluation, HIV-related stigma and discrimination, Healthcare settings, Ethiopia

Posted Date: July 12th, 2019

DOI: https://doi.org/10.21203/rs.2.11269/v1

License: (c) (i) This work is licensed under a Creative Commons Attribution 4.0 International License. Read Full License 


\section{Abstract}

Objective This objective of this project was to develop and contextualize guideline recommendations to reduce HIV-related stigma and discrimination (SAD) in Ethiopian healthcare settings. Results A multidisciplinary expert panel comprising 13 experts was established. The panel suggested that the guideline should target both healthcare worker behaviors and attitudes, and institutional practices and programs. A systematic review of systematic reviews and best practice documents was conducted. An initial list of 31 recommendations was drafted through a content analysis of the included documents. Strength and quality of evidence were assigned for each recommendation using Grading of Recommendations, Assessment, Development and Evaluation (GRADE) approach. The initial recommendations were framed under the following themes: structural, information-based and skills building, contact and empowerment, biomedical, measurement of SAD, and steps to integrate SAD reduction into healthcare settings. The tentative recommendations were evaluated both internally and externally through a series of Delphi surveys using Guideline Implementability Appraisal (GLIA V2.0) checklist. Finally, we explored facilitators and barriers to implement the guideline using key informant interviews to develop a framework to guide dissemination, implementation, and evaluation of the guideline in the local health system of Ethiopia. Key words: Guideline development, guideline evaluation, HIV-related stigma and discrimination, Healthcare settings, Ethiopia

\section{Introduction}

Stigma and discrimination (SAD) continue to challenge stakeholders working on the prevention and control of human immunodeficiency visus (HIV) [1]. Institutional factors such as, shortages of supplies and lack of training programs, lack of appropriate policies, guidelines, standards and regress systems to address SAD contributed to the continuation of SAD-related to HIV [2]. These problems underscore the necessity of guidelines and evidence-informed interventions to tackle SAD and promote uniform practice among healthcare workers [3-6].

Organizations have been working to reduce SAD related to HIV for decades [7, 8]. Part of the global response has been developing resource materials that guide SAD reduction interventions. However, some of these materials and tools are too broad and not context and population specific $[9,10]$. Most guidelines and best practices developed to reduce SAD reduction in healthcare settings lack detailed description on their methods of development and most of them are not up-to-date [11]. This poses a challenge in making an informed choice in prioritizing the interventions.

Guideline development generally involves establishing the guideline panel, determination of the scope of the guideline, searching for evidence, selecting the evidence, extracting and synthesizing the results, assessing quality, interpreting results, developing evidence statements and internal and external evaluation of the guideline $[12,13]$. The quality of evidence of guideline recommendations is assessed using the Grading of Recommendations, Assessment, Development and Evaluation (GRADE) approach [14]. Additionally, strength of a recommendation, or the extent to which one can be confident that the 
desirable effects of the recommended actions outweigh the undesirable effects are incorporated in developing guideline recommendations [15-17]. The World Health Organization (WHO) handbook for guideline development provides four criteria to judge the strength of recommendations: a) quality of evidence. $b$ ) balance of benefits versus harms, $c$ ) values and preferences and d) resource use [13].

Currently, to the best of our knowledge, there is no up-to-dated guideline developed systematically based on the procedures mentioned above to reduce HIV-related SAD in the heathcare settings. To address this gap, this project aimed at developing and contextualizing an evidence-informed guideline to reduce HIVrelated SAD in the healthcare settings.

\section{Methods And Materials}

The guideline development involved the following procedures: establishment of the guideline panel; determining the scope of the guideline; and searching, assessment and analyses of evidence; developing a tentative list of recommendations; establishing consensus and contextualizing the recommendations.

\section{Establishing the guideline panel}

We established a guideline panel that comprised researchers, program managers and HCWs. Then, we invited experts who were willing to be part of the panel to a half-day meeting held on July 17, 2016 and the guideline panel membership was formally established. We required all panel members to complete a declaration of conflicts of interests (S1) before contributing towards the development of the guideline. Members of the panel identified existing guidelines for inclusion and assisted in determining the scope of the guideline and developing guideline questions. All the panel members evaluated the draft guideline using the Guideline Implementability Appraisal (GLIA) v.2.0 checklist [18]. The evaluation has been described elsewhere [19].

\section{Determining the scope of the guideline}

The scope of the guideline was informed through the results of two systematic reviews as well as informal and formal consultation with experts.

\section{Searching, assessment and analysis of global evidence}

The search for international evidence on reduction of stigma and discrimination commenced with the systematic review of guidelines, best practices, standards and systematic reviews. The results of this search were reported elsewhere [20]. Following that, we conducted a systematic review of quantitative evidence [21] to identify interventions effective in reducing SAD in the healthcare settings.

\section{Development of guideline recommendations}


The guideline recommendations were developed through an inductive content analysis [22] of previous documents produced through systematic literature search $[20,21]$. While extracting data from the documents, the guideline panel considered the content, duration, mode of delivery, context, recipients and acceptability of the recommendations in the local context. For each recommendation, along with the panel members, we assigned strength and quality of evidence using a software developed by GRADE working group [14]. Quality of evidence was assigned as high, moderate, low or very low [15]. To assign strength of evidence for each recommendation, we used the World Health Organization (WHO) handbook for guideline development as a guidance [16].

We worded the recommendations considering the quality and the strength of evidence associated with the recommendations. We worded recommendations having strong evidence for the associated intervention as "must", "should", "need to" and other strong words [16]. On the other hand, we worded recommendations with weak evidence supporting the associated interventions with weak terms such as "may," "might," and similar words [16]. We have also included good practice points in the guideline. We made these statements for areas where providing a GRADE of evidence was not practical, and the panel believed that the statements were necessary. We considered good practice statements in the following situations [23]:

a) In cases where there was high quality indirect linked evidence supporting the recommended action.

b) In case where the panel was confident that the net benefit of the recommended action outweighed the risks, and the recommended action was feasible.

c) If without the message practitioners failed to execute the action and the practice issue needed to be consistent and failure to adhere to the practice is considered as the violation of human rights.

d) If the panel considered that the collection of further evidence was a wise use of time or impractical.

To date, whether these statements (good practice points) should be presented separately or along with GRADE recommendations is a matter of debate [24]. In the current guideline document, we indicated the good practice statements were not developed using GRADE approaches and they were labeled with a 'good practice point' sub-heading.

We substantiated each recommendation with detailed descriptions by referring to the original documents and the primary studies. We used the findings of two qualitative syntheses to support the meaningfulness of the interventions for PLHIV. Using these lists of recommendations and their respective descriptions, we finally drafted the guideline. The drafted guideline was then evalauted by a panel of experts using a Delphi technique, which has been reported elsewhere [19]. Finally, facilitators and barriers to implement the guideline were explored to contextualize the guideline to the Ethiopian healthcare settings. This contextualization study has been reported somewhere else [25].

Phases involved in the development of the guideline are summarised in Fig 1. 
Fig 1: Phases in the development of the guideline

\section{Results}

\section{Establishing the guideline panel}

We established a multidisciplinary guideline panel comprising researchers, health managers and health professionals. The multidisciplinary team comprised health managers, internists, HIV treatment coordinator, sociologist, psychiatrists, psychologist, nurses, health promotion and health service management experts.

\section{Determining the scope of the guideline}

Through an informal consultation of health managers, health professionals and researchers, we conducted the initial systematic review [26]. At the guideline panel meeting held on July 17, 2016, the scope of the guideline was limited to healthcare settings. Based on the consultation process, we developed the following guideline question:

Which type of interventions are effective in reducing stigma and discrimination among healthcare workers directed towards PLHIV, people affected by the virus and people associated with the virus?

\section{Development of recommendations}

We extracted recommendations from six guideline-related documents and six systematic reviews previously identified in the initial systematic search [20] and the systematic review of quantitative evidence [21]. Based on the content analyses of the guidelines, best practice documents, systematic reviews and the linked/cited research evidence, we initially developed 31 recommendations. These recommendations were subjected to a Delphi investigation through which some recommendations were modified, merged or dropped based on consideration and judgment of the guideline panel. Finally, the recommendations were presented under four thematic areas of interventions:
A. Structural interventions
B. Information-based and skills building approaches
C. Contact and empowerment approaches
D. Recommendations for research

The final list and desciption of recommendations are presented in the supplementary file (S2 Doc). Additionally, tools that assist in monitoring and evaluation of the implementation of the guideline were adapted and developed. To assess the level of stigma and discrimination at facility level, the panel decided to use a checklist for a stigma-free facility environment and policies [27] developed by previous research to track the implementation of guideline (S3 Doc). Moreover, a short version of 'discrimination 
free health facility' checklist was adapted from the UNAIDS/WHO agenda for stigma free healthcare facilities [28] and was included as part of the guideline. The panel decided that this checklist should be posted at service points (S4 Doc). Moreover, the panel has developed reminders that will be posted as checkpoints at service delivery points (S5 Doc). The tool was developed with the considerations of the manifestations of stigma to alert HCWs and let them examine the appropriateness of their practices. These reminders and checkpoints will enable health professionals to evaluate their own attitudes and actions. Additionally, we have adapted a framework for addressing SAD in healthcare facilities (Fig 2).

Fig 2. Framework for addressing stigma and discrimination in healthcare facilities (adapted from Jain, 2012[29])

\section{Discussions}

This project attempted to develop and contextualize an evidence-informed guideline to reduce HIV-related stigma and discrimination through a systematic search and analysis of global evidence. When planning and developing a guideline, health managers are always confronted with the challenges of addressing broad research questions with limited resources and time frames. As a remedy to address this challenge, scholars have developed different options for utilizing pre-processed research evidence [30].

The initial purpose of the current project was to utilize existing pre-processed evidence based on the 6S hierarchy of evidence [30]. Such an approach increases the efficiency of guideline development processes [31]. Although there were systematic reviews, guidelines and best practice documents in the field of stigma and discrimination related to HIV, those guidelines, best practice documents and systematic reviews were not presented in a way that they could help in the evaluation of the quality and strength of recommendations. Such information would have been helpful for prioritizing alternative recommendations and in convincing stakeholders about the preferred interventions.

For the current project, after the detailed analysis of the contents of guideline-related documents and systematic reviews we outlined recommendations were framed under the following themes: structural, information-based and skills building, contact-based interventions and recommendations for further research. While assessing the strength of the recommendations, the guideline panel has taken local circumstances and policy environment into account. This makes the current guideline relatively more practical as compared to previous guidelines and best practices in that it will enable policy makers to prioritize the recommendations.

Evidence utilization is successful only if it considers local factors [32]. The appropriateness of these recommendations depends on local factors related to healthcare facilities [33]. For the current guideline, the initial recommendations were drawn from global literature and not from local studies. Initially, the appropriateness of implementing the recommendations to the local context and their acceptability by local implementers was not known. Hence, we evaluated by the appropropriateness and applicability of the guideline using GLIA checklist [18] both by a local guideline panel and an external panel [21]. This 
evaluation has considered both rigor and feasibility issues. Moreover, additional contextual data that assists in dissemination, implementation and evaluation of the guideline were generated and reported [21].

In conclusion, we framed the recommendations under the following themes: structural, information-based and skills building, contact and empowerment and recommendations for research. The appropriateness of these recommendations to the local context was also evaluated and additional data on dissemination, implementation of the guideline was generated. Implementers can use the information generated during the multiple phases of the project while disseminating, implementing and evaluating the guideline.

\section{Limitations}

The guideline was developed with the consideration of the local context of Jimma Medical Center, which may not necessarily be transferred to other contexts. In addition, the quality of the available evidence on interventions to address stigma and discrimination is poor.

\section{Declarations}

\section{Ethical approval and consent to participate}

This research project received ethical approval from the Human Research Ethics Committee of the University of Adelaide (approval number H-2016-140) and from the Institutional Review Board of Jimma University Institute of Health (RPGC/389/2016). Written consent forms were obtained from all participants before their participation in the project. During the write-up and report writing, participants were not identified by their names, positions or roles; only codes were used. Consent was obtained from guideline panel members before including their names in the main guideline.

\section{Consent to publish}

Not applicable.

\section{Availability of data and materials}

All data were reported in the main manuscript.

\section{Competing interests}

The authors declare that they have no competing interests. 


\section{Funding}

This study was conducted as part of GTF's PhD project which was supported by the Adelaide scholarship International granted by the University of Adelaide. The authors did not receive any funding for this research.

\section{Authors' contribution}

Conceptualization: GTF, CL, MW and ZM.

Data curation: GTF, CL, MW and ZM.

Formal analysis: GTF.

Methodology: GTF, CL, MW and ZM.

Project administration: GTF.

Validation: GTF, CL, MW and ZM.

Visualization: GTF, CL, MW and ZM.

Writing - original draft: GTF.

Writing - review \& editing: GTF, CL, MW and ZM.

\section{Acknowledgments}

The authors are grateful to the guideline panel and other study participants for devoting their time for the success of the project.

\section{References}

1. Parker R, Aggleton P. HIV and AIDS-related stigma and discrimination: a conceptual framework and implications for action. Social science \& medicine. 2003;57(1):13-24.

2. Stangl AL, Lloyd JK, Brady LM, Holland CE, Baral S. A systematic review of interventions to reduce HIVrelated stigma and discrimination from 2002 to 2013: how far have we come? Journal of the International AIDS Society. 2013;16(3Suppl 2):18734. doi: 10.7448/IAS.16.3.18734. PubMed PMID: PMC3833106. 
3. Bos AE, Schaalma HP, Pryor JB. Reducing AIDS-related stigma in developing countries: the importance of theory- and evidence-based interventions. Psychol Health Med. 2008;13(4):450-60. Epub 2008/10/01. doi: 10.1080/13548500701687171. PubMed PMID: 18825583.

4. Wodajo BS, Thupayagale-Tshweneagae G, Akpor OA. Stigma and discrimination within the Ethiopian health care settings: Views of inpatients living with human immunodeficiency virus and acquired immune deficiency syndrome. African Journal of Primary Health Care \& Family Medicine. 2017;9(1):1314. doi: 10.4102/phcfm.v9i1.1314. PubMed PMID: PMC5566131.

5. Salih MH, Tessema GA, Cherkos EA, Ferede AJ, Zelalem Anlay D. Stigma towards People Living on HIV/AIDS and Associated Factors among Nurses' Working in Amhara Region Referral Hospitals, Northwest Ethiopia: A Cross-Sectional Study. Advances in Nursing. 2017;2017.

6. Feyissa GT, Abebe L, Girma E, Woldie M. Stigma and discrimination against people living with HIV by healthcare providers, Southwest Ethiopia. BMC Public Health. 2012;12:522. Epub 2012/07/17. doi: 10.1186/1471-2458-12-522. PubMed PMID: 22794201; PubMed Central PMCID: PMCPmc3506482.

7. Annie Michaelis P, Vaishali Mahendra M. Reducing HIV-Related Stigma: Lessons Learned from Horizons Research and Programs. Public Health Reports. 2010;125.

8. Mboya-Brown; R, Nyblade; L, Reeves M, Maclinnis R. Scaling up Stigma Reduction in Health Facilities: Outcomes of a Health Policy Project Expert Consultation. HPP; 2015.

9. USAID. Health Policy Initiative. Programmatic Guidance for Reducing HIV and Key Population Stigma and Discrimination: For the Greater Mekong Region Countries of Thailand, Lao PDR and Myanmar. Bangkok, Thailand: USAID; 2012.

10. UNAIDS. Reducing HIV stigma and discrimination: A critical part of national AIDS programmes: A resource for national stakeholders in the HIV response: Joint United nations programme on HIV/AIDS (UNAIDS); 2007.

11. PHR. Guide to Reducing Stigma and Discrimination in the Health Sector 2011 [cited 2016 01/11/2016]. Available from: http://physiciansforhumanrights.org/library/other/stigma-reductionguide.html.

12. Developing NICE guidelines: the manual: National Instutites for Health and Clinical Excellence. ; 2014. Available from: https://www.nice.org.uk/process/pmg20/chapter/introduction-and-overview.

13. WHO handbook for guideline development: World Health Organization; 2014.

14. GRADEpro G. GRADEpro Guideline Development Tool [Software]. McMaster University. 2015.

15. Atkins D, Best D, Briss PA, Eccles $M$, Falck-Ytter Y, Flottorp S, et al. Grading quality of evidence and strength of recommendations. Bmj. 2004;328(7454):1490. Epub 2004/06/19. doi:

10.1136/bmj.328.7454.1490. PubMed PMID: 15205295; PubMed Central PMCID: PMCPMC428525. 
16. Bertone MP, Wurie H, Samai M, Witter S. The bumpy trajectory of performance-based financing for healthcare in Sierra Leone: agency, structure and frames shaping the policy process. Globalization and health. 2018;14(1):99. Epub 2018/10/22. doi: 10.1186/s12992-018-0417-y. PubMed PMID: 30342544; PubMed Central PMCID: PMCPMC6195985.

17. Andrews JC, Schunemann HJ, Oxman AD, Pottie K, Meerpohl JJ, Coello PA, et al. GRADE guidelines: 15. Going from evidence to recommendation-determinants of a recommendation's direction and strength. J Clin Epidemiol. 2013;66(7):726-35. Epub 2013/04/11. doi: 10.1016/j.jclinepi.2013.02.003. PubMed PMID: 23570745.

18. Kashyap N, Dixon J, Michel G, Brandt C. GuideLine Implementability Appraisal v. 2.0 New Haven, CT: Yale University: Yale Center for Medical Informatics; 2005 [30/04/2015]. Available from: http://gem.med.yale.edu/glia/doc/GLIA_v2.pdf.

19. Feyissa GT, Lockwood C, Woldie M, Munn Z. Evaluation of a guideline developed to reduce HIV-related stigma and discrimination in healthcare settings and establishing consensus. PloS one. 2018;13(7):e333229.

20. Feyissa GT, Lockwood C, Woldie M, Munn Z. Reducing HIV-related stigma and discrimination in healthcare settings: a systematic review of guidelines, tools, standards of practice, best practices, consensus statements and systematic reviews. Journal of Multidisciplinary Healthcare. 2018;11:405-16.

21. Feyissa GT, Lockwood C, Woldie M, Munn Z. Reducing HIV-related stigma and discrimination in healthcare settings: A systematic review of quantitative evidence. PloS one. 2019;14(1):e0211298.

22. Hsieh HF, Shannon SE. Three approaches to qualitative content analysis. Qual Health Res. 2005;15(9):1277-88. Epub 2005/10/06. doi: 10.1177/1049732305276687. PubMed PMID: 16204405.

23. Guyatt GH, Schünemann HJ, Djulbegovic B, AkI EA. Guideline panels should not GRADE good practice statements. Journal of clinical epidemiology. 2015;68(5):597-600.

24. Guyatt GH, Alonso-Coello P, Schünemann HJ, Djulbegovic B, Nothacker M, Lange S, et al. Guideline panels should seldom make good practice statements: guidance from the GRADE Working Group. Journal of Clinical Epidemiology. 2016;80:3-7. doi: http://dx.doi.org/10.1016/j.jclinepi.2016.07.006.

25. Feyissa GT, Munn Z, Woldie M, Lockwood C. Exploration of facilitators and barriers to the implementation of a guideline to reduce HIV-related stigma and discrimination in the Ethiopian healthcare settings: A descriptive qualitative st. PloS one. 2019;14(9).

26. Elo $S$, Kyngas $H$. The qualitative content analysis process. J Adv Nurs. 2008;62(1):107-15. Epub 2008/03/21. doi: 10.1111/j.1365-2648.2007.04569.x. PubMed PMID: 18352969.

27. Horizons S. Population Council: The PLHA-friendly achievement checklist: a self-assessment tool for hospitals and other medical institutions caring for people living with HIV/AIDS (PLHA). New York. 2003. 
28. UNAIDS. Agenda for Zero Discrimination in Healthcare Settings 2017 [cited 2017 March 12]. Available from: http://www.unaids.org/sites/default/files/media_asset/2017ZeroDiscriminationHealthCare.pdf.

29. Jain A, Nyblade L. Scaling up policies, interventions, and measurement for stigma-free HIV prevention, care and treatment services. Washington, DC: The Health Policy Project. 2012.

30. Dicenso A, Bayley L, Haynes RB. Accessing pre-appraised evidence: fine-tuning the $5 S$ model into a $6 S$ model. Evid Based Nurs. 2009;12(4):99-101. Epub 2009/09/26. doi: 10.1136/ebn.12.4.99-b. PubMed PMID: 19779069.

31. Rosenfeld RM, Shiffman RN. Clinical practice guidelines: a manual for developing evidence-based guidelines to facilitate performance measurement and quality improvement. Otolaryngology--Head and Neck Surgery. 2006;135(4 suppl):S1-S28.

32. Eisenberg JM. Globalize the evidence, localize the decision: evidence-based medicine and international diversity. Health affairs. 2002;21(3):166-8.

33. Harrison MB, Légaré F, Graham ID, Fervers B. Adapting clinical practice guidelines to local context and assessing barriers to their use. Canadian Medical Association Journal. 2010;182(2):E78-E84.

\section{Supplementary File Legend}

S1 Doc: Declaration of conflict of interest. This file shows a format through which guideline panle members declared potential conflcits of interests.

S2 Doc: Recommendations included in the guideline. This file presents recommendations included in the final guideline along with their descriptions.

S3 Doc: Facility assessment checklist (PLHIV Friendly checklist for healthcare facilities). This file presents a checklist to check health facilities whether they are PLHIV friendly or not.

S4 doc: Discrimination free checklist poster. This file presents a shorty version of discrimination free health facility checklist which is to be used for post on service points. The file was adapted from UNAIDS/WHO agenda for stigma free healthcare facilities.

S5 doc: Reminders for health professionals. This file presents reminders and checkpoints to be posted at service delivery point which enables health professionals to evaluate their own attitudes and actions.

\section{Figures}




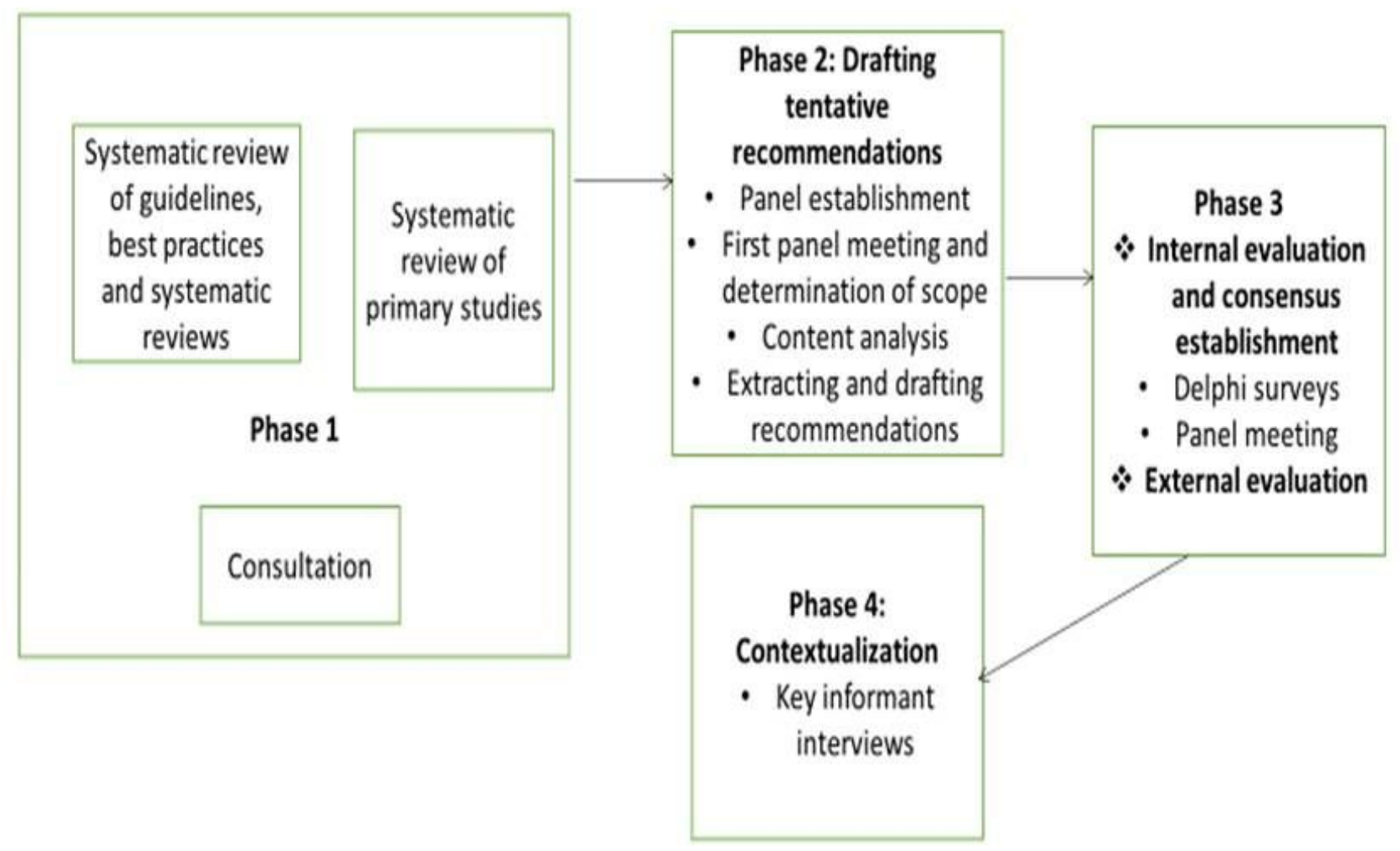

Figure 1

Phases in the development of the guideline 


\section{Framework for addressing stigma and discrimination in Healthcare settings(Adapted from Jain,2012)}

\begin{tabular}{|c|c|c|c|}
\hline $\begin{array}{l}\text { Levels / targets of } \\
\text { intervention }\end{array}$ & Manifestations of stigma & $\begin{array}{l}\text { Determinants/Actionable } \\
\text { drivers and facilitators }\end{array}$ & Candidate Interventions \\
\hline Institutional & $\begin{array}{l}\text { - Segregation of clients } \\
\text { Marking files } \\
\text { - Physical isolation of } \\
\text { service points }\end{array}$ & $\begin{array}{l}\text { - Lack of supportive policies } \\
\text { and SOPS, } \\
\text { - Lack of timely delivery of } \\
\text { supplies and } \\
\text { - Weak /absence of routine } \\
\text { training and supervision } \\
\text { programs }\end{array}$ & $\begin{array}{l}\text { Structural } \\
\text { - Organizational SOPS, } \\
\text { policies, } \\
\text { - Strong training and } \\
\text { supervision programs } \\
\text { - Reporting and redress } \\
\text { system } \\
\text { - Availing supplies }\end{array}$ \\
\hline HCWs & $\begin{array}{l}\text { - Blame, } \\
\text { - Denial of care, } \\
\text { - Substandard care, } \\
\text { - Breaches of } \\
\text { confidentiality } \\
\text { - Secondary stigma }\end{array}$ & $\begin{array}{l}\text { - Irrational fear, } \\
\text { - Prejudices, } \\
\text { - Limited knowledge of } \\
\text { S\&D }\end{array}$ & $\begin{array}{l}\text { - Information } \\
\text { - } \text { skills-building } \\
\text { approaches } \\
\text { - structural approaches }\end{array}$ \\
\hline PLHIV & $\begin{array}{l}\text { Internalized stigma, self } \\
\text { isolation, avoidant coping }\end{array}$ & $\begin{array}{l}\text { Actual or anticipated stigma } \\
\text { from others }\end{array}$ & $\begin{array}{l}\text { Empowerment and } \\
\text { psychosocial support }\end{array}$ \\
\hline
\end{tabular}

\section{Figure 2}

Framework for addressing stigma and discrimination in healthcare facilities (adapted from Jain, 2012[29])

\section{Supplementary Files}

This is a list of supplementary files associated with this preprint. Click to download.

- S2Docguidelinerecommendations.docx

- S1DocDeclarationofconflictofinterest.doc

- S3DocFacilityassessmentchecklist.docx

- S4DocDiscriminationfreechecklistshortversion.docx

- S5DocRemindersforhealthprofessionals.docx 